\title{
Czynnošć nadgłośniowa gardła i krtani towarzysząca wyrażaniu emocji
}

\section{Supraglottal activity of larynx and pharynx accompanying the expression of emotion}

\author{
Ewa Kazanecka ${ }^{1}$, Agnieszka Borowiec $^{2}$, Agata Szkiełkowska ${ }^{1,3}$ \\ ${ }^{1}$ Uniwersytet Muzyczny Fryderyka Chopina, Katedra Audiologii i Foniatrii, Warszawa \\ ${ }^{2}$ Uniwersytet Warszawski, Instytut Polonistyki Stosowanej, Warszawa \\ ${ }^{3}$ Instytut Fizjologii i Patologii Słuchu, Światowe Centrum Słuchu, Warszawa/Kajetany
}

Adres autora: Ewa Kazanecka, Uniwersytet Muzyczny Fryderyka Chopina, ul. Okólnik 2, 00-368 Warszawa, e-mail: ewkazanecka@gmail.com

\section{Streszczenie}

Wstęp: Wyrażanie emocji związane jest z określonym modelem prozodycznym, czyli różni się zakresem wysokości i dynamiki głosu. Celem pracy było zbadanie czynności gardła i krtani towarzyszącej okazywaniu różnych emocji.

Materiał i metoda: Materiał stanowiło 16 osób. Ruchy gardła i krtani były nagrywane z wykorzystaniem wideonasofiberoskopii, podczas ciągłej fonacji głoski [i] najpierw bez emocji, na różnej wysokości i głośności, a następnie podczas wyrażania emocji: gniewu, radości, strachu, smutku, zdziwienia, obrzydzenia i pogardy. Przeanalizowano 160 obrazów wideo nagranych podczas fonacji każdego zadania. Porównywano stopień kompresji przestrzeni nadgłośniowych dla fonacji z wyrażaniem emocji i bez emocji. Jednocześnie oceniano, jaka cecha głosu dominuje w każdym typie emocji.

Wyniki: W obrazach fiberoskopowych gardła i krtani uzyskanych w przebiegu fonacji z wyrażaniem emocji stwierdzano większą kompresję niż na obrazach pochodzących z fonacji dźwięku wygodnego, bez emocji. Największy stopień kompresji gardła dolnego i przedsionka krtani stwierdzono dla obrzydzenia, pogardy i gniewu, najmniejszy dla strachu i smutku oraz radości.

Wnioski: Czynność toru nadgłośniowego zależy od jakości tworzonego głosu i intencji wypowiedzi.

Słowa kluczowe: czynności nadgłośniowe • emocje • prozodia • nasofiberoskopia

Abstract

Introduction: Expressing emotions is related to a specific prosodic model, which varies in height and dynamic range of the voice.

Aim: The aim of this study was to investigate the activities of the throat and larynx accompanying the manifestation of different emotions.

Material and method: The material consisted of 16 people. Pharyngeal and laryngeal movements were recorded using videonasofiberscopy while a subject was performing sustained phonation [i] first without emotions at different heights and volume and then expressing emotions: anger, joy, fear, sadness, surprise, disgust and contempt. 160 video images recorded from the phonation of each task were analyzed. Compression of supraglottic space for phonation of expressed emotion and without emotion was compared. At the same time was assessed which voice feature predominates in any type of emotion.

Results: In the fiberoskopic pictures of pharynx and larynx recorded during phonation with expressing emotions greater compression was obtained than in the images from the sound phonation comfortable without emotion. The greatest degree of compression of hypopharynx and larynx vestibule was found for disgust, contempt and anger for fear of the smallest and sadness and joy.

Conclusions: Activity of the vocal tract depends on the quality of voice and intention of expression.

Key words: supraglottal activity $\bullet$ emotion $\bullet$ prosodia $\bullet$ nasofiberoscopy 


\section{Wstęp}

Emocje są ważnym czynnikiem wpływającym na tworzenie głosu. Te psychofizjologiczne stany związane są z przygotowaniem organizmu do odpowiedniej reakcji, zależnie od różnych sytuacji życiowych [1,2]. Emocje pojawiły się w toku ewolucji. Związane są z aktywnością ośrodkowego układu nerwowego, głównie pnia mózgu i układu limbicznego, a ciało jest obszarem ekspresji [1].

Związek emocji z procesem tworzenia głosu wynika zarówno z funkcji komunikatywnej języka, jak i z reakcji somatycznych towarzyszących emocjom. U człowieka głos, obok mimiki twarzy, jest narzędziem ekspresji [3]. Informacja o rodzaju emocji zaszyfrowana jest w linii melodycznej głosu. Tempo mówienia, wysokość i głośność głosu ulegają zmianie w zależności od uczuć człowieka.

Wpływ emocji na proces tworzenia głosu wynika również z ich oddziaływania na podstawowe funkcje fizjologiczne człowieka, to jest na oddychanie i napięcie mięśniowe. Generowanie głosu i wydobycie go na zewnątrz związane jest z precyzyjną pracą wielu mięśni, a oddychanie jest jednym $\mathrm{z}$ trzech głównych procesów emisji głosu. W wielu wypadkach niekorzystnie zmodyfikowane czynności ruchowe nadmiernie obciążają narząd głosowy, stąd czynniki emocjonalne wymieniane są jako czynniki etiologiczne zaburzeń głosu [4].

W piśmiennictwie jest wiele prac dotyczących roli sygnału akustycznego w procesie przekazywania emocji. W badaniach wykorzystywana jest głównie ocena subiektywna i analiza akustyczna fragmentów mowy [5-11]. Informacje o kodzie głosowym emocji zawartym w próbkach mowy uzyskiwane są z parametrów akustycznych takich jak czas trwania, częstotliwość podstawowa, formanty, energia akustyczna. Korelowane są one z odczuciami słuchających sędziów, których zadaniem jest rozpoznanie rodzaju emocji. Najczęściej emocje te są symulowane przez mówcę. Naturalne emocje zawarte $\mathrm{w}$ mowie, powstałe $\mathrm{w}$ konkretnych sytuacjach, są trudne do zarejestrowania - w badaniach wykorzystuje się najczęściej nagrania pochodzące $\mathrm{z}$ mediów [10].

Sygnały akustyczne emocji są dobrze rozpoznawalne w mowie [6,9], nawet w próbkach, w których emocje $\mathrm{w}$ głosie uzyskiwane są w warunkach doświadczalnych. Badania pozwoliły dość dobrze poznać akustyczne profile poszczególnych emocji. Jedne emocje są lepiej rozpoznawalne, inne gorzej $[11,12]$. Najlepiej identyfikowane są złość i smutek, słabiej radość.

Juslin [6] rozszerzył badania dźwiękowego kodu emocji i porównywał cechy akustyczne dla próbek głosowych i materiału muzycznego pochodzącego $\mathrm{z}$ wykonań instrumentalnych. Odnalazł wspólne cechy kodujące podstawowe emocje dla obu przekazów.

W piśmiennictwie niewiele jest prac przedstawiających wpływ emocji na aktywność traktu głosowego. Niemożliwa jest ocena czynności ruchowej traktu głosowego w naturalnych sytuacjach związanych z konkretnymi emocjami. Dostępne są jedynie warunki symulacji. Badane są różnice w czynnościach traktu głosowego podczas wymawiania tego samego tekstu, ale $\mathrm{z}$ intencją odtwarzania różnych emocji.

Lee [13] badał aktywność artykulacyjną, rejestrując ruchy końca języka, dolnej wargi i żuchwy przy użyciu artykulografu magnetycznego (system EMA) dla czterech emocji symulowanych w głosie przez jedną osobę. Obserwacje wykazały zwiększony zakres i szybkość ruchów, szczególnie końca języka, podczas mowy wyrażającej złość, a zmniejszone dla mowy wyrażającej smutek. Aktywność artykulacyjna dla radości była zbliżona do mowy neutralnej. Jego kolejne badania, wykorzystujące technikę szybkiego obrazowania MRI, poszerzone zostały o ocenę gardła, niżej położonej części traktu nadgłośniowego [14]. Potwierdziły one wcześniejsze wyniki, a także pokazały większe wykorzystanie regionu gardła przy uzewnętrznianiu złości oraz skracanie traktu głosowego leżącego powyżej fałdów przedsionkowych przy ekspresji szczęścia.

Inną techniką wykorzystywaną do badania narządu głosu jest nasofiberoskopia. Zastosowanie giętkich endoskopów wprowadzanych przez nos umożliwia obserwację czynności traktu nadgłośniowego w trakcie mówienia i śpiewania. Interpretacja obrazu nastręcza jednak wiele trudności. Konfiguracja gardła dolnego oraz położenie elementów anatomicznych przedsionka krtani ulegają ciągłej zmianie, zależnie od różnych czynników, np. rodzaju artykułowanej głoski czy jakości głosu. Zmiany wysokości, głośności lub celowy dodatek innej cechy głosu, związane są z ruchami w obrębie nadgłośniowego traktu głosowego [15]. Dla tych samych zadań głosowych obserwuje się u różnych ludzi odmienne wzorce czynnościowe i różny zakres ruchu.

Dotychczasowe prace koncentrowały się na związku obecności ruchów przedsionka krtani z patologią głosu, szczególnie zaburzeniami czynnościowymi [16-21]. Analizowano ruchy przywodzenia fałdów przedsionkowych, zwane kompresją boczną (FVF), oraz zbliżanie chrząstek nalewkowatych do podstawy nagłośni, zwane kompresją przednio-tylną (AP). Interpretację wyników utrudnia częste występowanie powyższych ruchów u osób niezgłaszających zaburzeń głosu oraz brak korelacji zwiększenia aktywności nadgłośniowej w grupie osób z guzkami głosowymi $[18,21]$. Stranger $[18,20]$ wyraża przypuszczenie, że aktywność nadgłośniową, która pojawia się jako element niestały fonacji, tzw. dynamiczny komponent FVF i AP, można traktować jako udział krtani w artykulacji.

Ta zmienność w występowaniu i nasileniu czynności nadgłośniowych u różnych osób była dla autorów inspiracją do badań nad związkiem między motoryką gardła dolnego i przedsionka krtani a ekspresją emocji.

\section{Cel}

Celem pracy było zbadanie, jak wyrażenie emocji wpływa na konfigurację toru głosowego. Autorzy wysunęli hipotezę, że na czynności gardła dolnego i przedsionka krtani będzie miała wpływ linia melodyczna zadania głosowego i inne cechy jakości głosu, w których jest zaszyfrowana informacja o przekazywanym rodzaju emocji, a także uruchamiane automatycznie wzorce ruchowe zapamiętane $\mathrm{z}$ sytuacji emocjonalnych. 


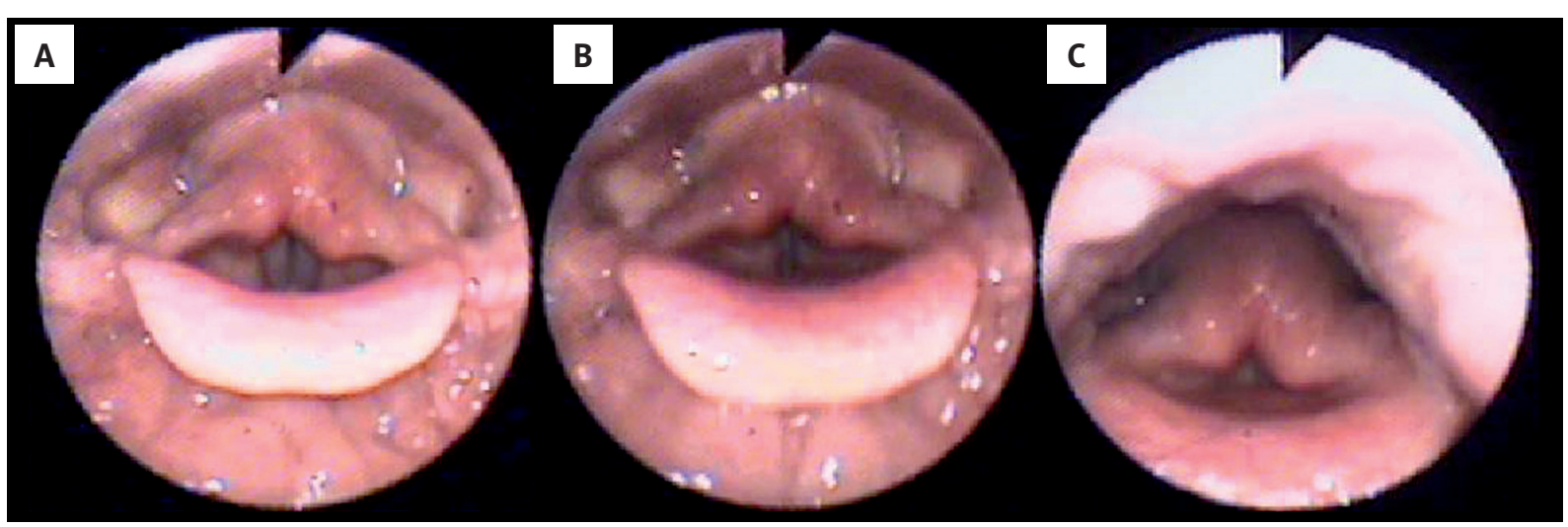

Rycina 1. (A-C) Przykłady oceny intensywności ruchów traktu nadgłośniowego w obrazach wideofiberoskopowych jako miernik stopnia kompresji gardła dolnego i przedsionka krtani, ocenianych w skali od 0 do 3 punktów [15]. G - kompresja przestrzeni gardła (ruch ścian gardła); AP - kompresja przednio-tylna (ruch chrząstek nalewkowatych w kierunku podstawy nagłośni); FVF - kompresja fałdów przedsionkowych (przywiedzenie fałdów przedsionkowych). (A) G1 + AP1,5 + FVF0 $\sum 2,5$ pkt; (B) G1 + $\mathrm{AP} 1,5+\mathrm{FVF} 2,5 \sum 5 \mathrm{pkt} ;$ (C) G3 + AP2,5 + FVF1,5 $\sum 7$ pkt

Figure 1. (A-C) Examples of the assessment of the intensity of the supraglottal vocal tract movements in the videofiberoscopic images, as a measure of the degree of compression of the hypopharynx and larynx vestibule, evaluated on a scale 0-3 point [15]. $\mathrm{G}$ - compression of the pharynx space, AP - compression anterio-posterior (movement the arytenoid cartilages to the petiole of epiglottis), FVF - false vocal fold compression (adduction of the false vocal fold)

\section{Materiał i metoda}

Badania przeprowadzono u 16 osób. Do obserwacji traktu głosowego podczas zadań głosowych wykorzystano badanie nasofiberoskopowe. Endoskop był wprowadzony tak, by widoczne były zachyłki gruszkowate i wnętrze krtani. Dodatkowo, orientacyjnie (odsłuchowo) oceniano jakość głosu pod kątem wysokości, głośności i innych cech charakteryzujących daną emocję.

\section{Zadania głosowe}

W celu wyeliminowania wpływu artykulacji głoski, badanie przeprowadzano podczas fonacji tylko jednej głoski. Każda osoba najpierw wymawiała ciągłą głoskę [i] bez emocji, na wygodnej wysokości i głośności, wysoko z wygodną głośnością, nisko z wygodną głośnością oraz na wygodnej wysokości głośno. Następnie fonowała głoskę [i] z intencją wyrażenia sześciu podstawowych emocji: gniewu, radości, strachu, smutku, obrzydzenia, pogardy i zdziwienia.

Z nagranego filmu do dalszych badań wybierano klatki pochodzące $\mathrm{z}$ fonacji, kiedy czynność gardła i przedsionka krtani wykazywała największą aktywność. Ocenie poddawane były ruchy ścian gardła dolnego i czynności nadgłośniowe, czyli ruchy dośrodkowe fałdów przedsionkowych i ruchy chrząstek nalewkowatych w stosunku podstawy nagłośni. Miarą zakresu ruchu był procent redukowanej przestrzeni zachyłków gruszkowatych oraz procent zasłanianej długości i szerokości fałdów głosowych. Każdy parametr oceniany był w skali od 0 do 3 punktów (rycina 1). Następnie dodawano punkty uzyskane dla poszczególnych parametrów, otrzymując łączny stopień kompresji dla przestrzeni gardła i przedsionka krtani.

Do ostatecznej analizy i porównań uzyskano dla każdego badanego po 10 parametrów: 4 dla fonacji neutralnej i 6 dla fonacji $\mathrm{z}$ emocjami.

\section{Wyniki}

Rycina 2 przedstawia różne czynności traktu nadgłośniowego podczas realizacji tej samej emocji - gniewu dla kilku osób. Każda z osób posłużyła się inną wysokością głosu. Wspólną cechą było wykorzystanie dość dużej głośności.

Z analiz wynika, że zmiany wysokości i głośności głosu zwiększają aktywność mięśniową w obrębie gardła i przedsionka krtani (rycina 3). Dla neutralnej fonacji średni stopień kompresji największy był dla głosu wysokiego oraz głośnego, przy czym podczas fonacji dźwięku głośnego badani często tworzyli głos nieco wyżej niż podczas dźwięku wygodnego.

Intencja wyrażania różnego typu emocji wprowadza dodatkową kompresję powyższych okolic. Największy stopień kompresji gardła dolnego i przedsionka krtani stwierdzono dla obrzydzenia, pogardy i gniewu, najmniejszy dla strachu i smutku oraz radości.

Wyniki orientacyjnej oceny cech jakości głosu, wykorzystanych przez badanych przy wyrażaniu poszczególnych emocji, zebrano w tabeli 1 . Zgodne są one $\mathrm{z}$ danymi z piśmiennictwa: gniew realizowany jest głośno i stosunkowo krótko, radość wysoko, smutek cicho i monotonnie. Dla niektórych emocji charakterystyczne było użycie dodatkowych cech wyrazu, takich jak szorstkość w obrzydzeniu i pogardzie, niestabilność głosu w strachu, przerwy podczas wyrażania radości, naśladujące śmiech.

Emocje związane z największą kompresją gardła dolnego i przedsionka krtani to jednocześnie duże zmiany głosu wykorzystane podczas ich realizacji. Obrzydzenie to niższy głos z szorstkością, gniew jest głośny i dość wysoki z domieszką parcia; smutek i strach nie powodują dużych zmian głosowych.

Najwyższą wysokością głosu badani posłużyli się, wyrażając radość. Nieco mniejszą przy zdziwieniu i gniewie. 


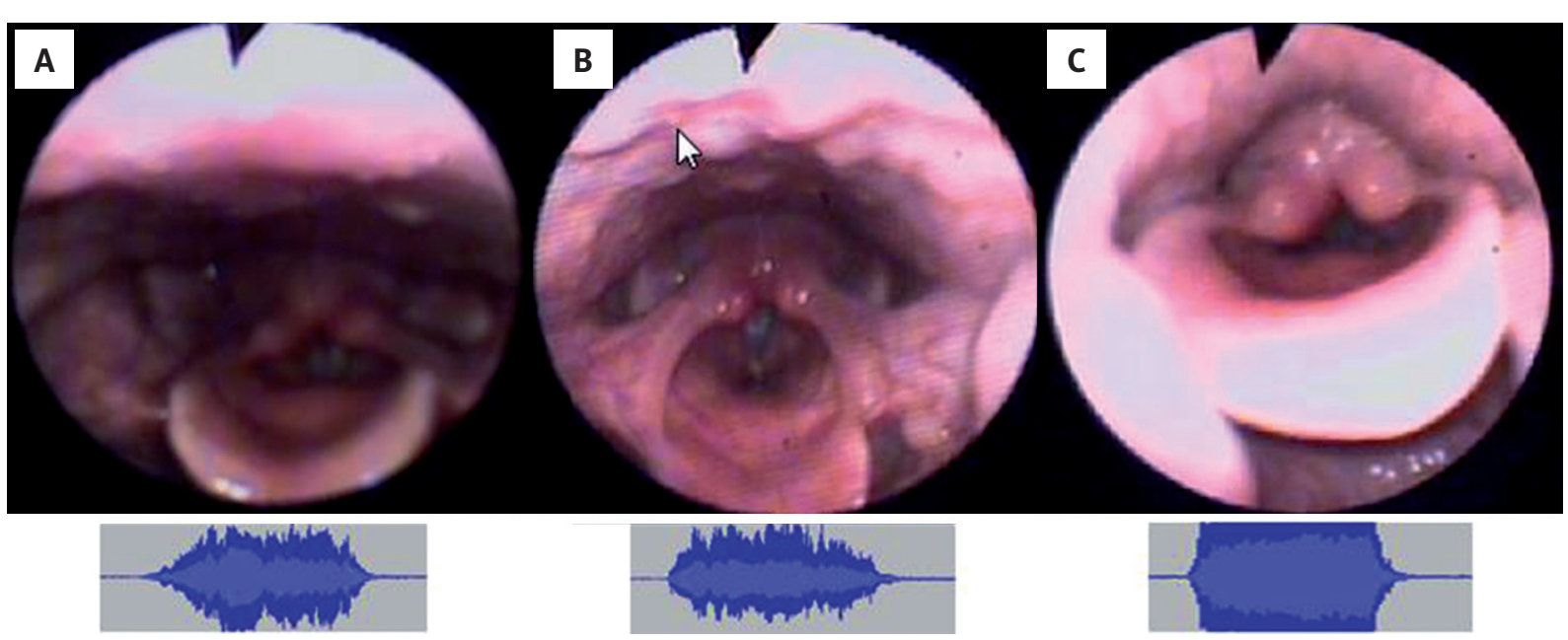

Rycina 2. (A-C) Różnice w czynnościach gardła dolnego i przedsionka krtani podczas fonacji głoski [i] z intencją wyrażania gniewu Figure 2. (A-C) The differences in the activities of the hypopharynx and larynx vestibule during phonation [i] with the intention of expressing anger

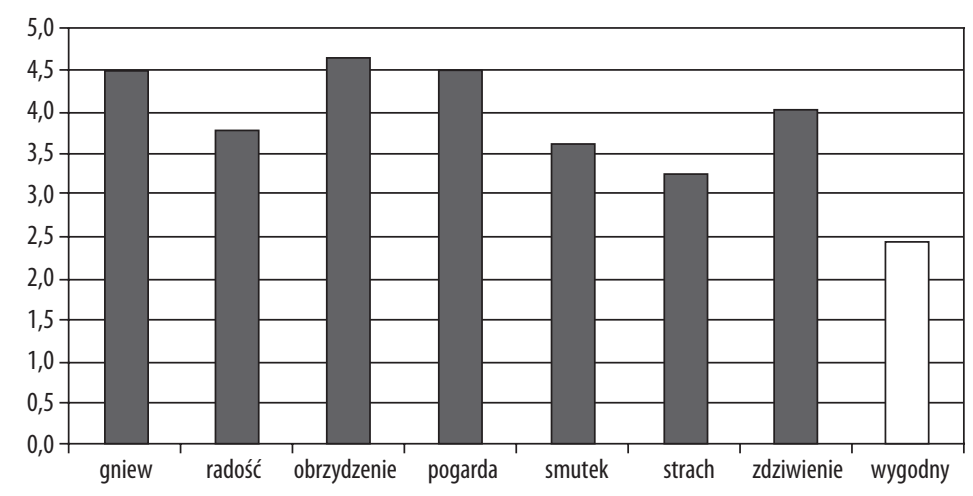

Rycina 3. Porównanie średniego stopnia kompresji gardła dolnego i przedsionka krtani dla fonacji ciągłej głoski [i] tworzonej z intencją różnych emocji oraz neutralnie o wygodnej wysokości i głośności

Figure 3. Comparison of the average compression of hypopharynx and larynx vestibule for continuous phonation [i] created with the intention of different emotions and neutral with a comfortable height and volume

Tabela 1. Cechy jakości głosu charakterystyczne dla poszczególnych emocji Table 1. Voice quality features specific for particular emotions

\begin{tabular}{|c|c|c|c|c|}
\hline \multirow{2}{*}{ Emocja } & \multicolumn{4}{|c|}{ Sposób tworzenia i jakość głosu } \\
\hline & Głośność & Wysokość & Czas & Dodatkowe cechy \\
\hline Gniew & ++++ & +++ & ++ & party, poprzedzony stęknięciem \\
\hline Radość & +++ & ++++ & ++++ & przerywany \\
\hline Pogarda & +++ & +++ & + & szorstkość (++) \\
\hline Obrzydzenie & ++ & ++ & ++++ & szorstkość (+++) \\
\hline Zdziwienie & +++ & ++++ & + & tryb pytający, ostry, piskliwy \\
\hline Strach & ++ & ++ & +++ & szept, niestabilny \\
\hline Smutek & + & ++ & ++++ & monotonny \\
\hline
\end{tabular}

Spośród tych trzech emocji, radości towarzyszyła najmniejsza kompresja okolic nadgłośniowych.

Podczas wyrażania obrzydzenia i pogardy u większości osób słyszalna była szorstkość. Ta cecha w połączeniu z niskim głosem, szczególnie w końcu frazy, dawała efekt dużego skrzypienia. Na poziomie traktu głosowego obserwowana była wzmożona czynność mięśniowa przedsionka krtani i gardła dolnego.

\section{Dyskusja}

Na czynność okolicy nadgłośniowwej traktu głosowego, którą można obserwować w filmach zarejestrowanych podczas badania nasofiberoskopowego, ma wpływ wiele czynników. Autorzy, badając tę czynność w trakcie symulowanej głosowej ekspresji różnych typów emocji, zauważyli, że składa się na nią indywidualna aktywność mięśniowa 
związana z realizacją dźwięku o określonej wysokości, głośności i barwie oraz wzorca ruchowego emocji danej osoby.

W badaniach stwierdzono silny wpływ wysokości głosu na zwiększoną aktywność mięśniową okolic znajdujących się w bliskim sąsiedztwie głośni. Im wysokość głosu bardziej odbiega od wygodnego poziomu, tym intensywniejszy ruch ścian gardła, przywodzenie fałdów przedsionkowych lub zbliżania nalewek do podstawy nagłośni.

Dodatkowy czynnik, tj. wyrażanie emocji różnego typu, nasila ruchy ścian gardła i przedsionka krtani. Prawdopodobnie związane jest to z dużymi zmianami jakości głosu, którymi posłużyli się badani w celu zrealizowania emocji i indywidualnymi wzorcami czynnościowymi wykształconymi w ciągu życia.

Zmiany jakości głosu tylko częściowo odpowiedzialne są za zwiększenie aktywności nagłośniowej traktu głosowego. Aktywność mięśniowa okolic nadgłośniowych była zwiększona nawet dla emocji, których realizacja związana była z niewielkimi zmianami głosu, kiedy to wysokość i głośność były na poziomie neutralnej, wygodnej fonacji.

Zaobserwowano, że jeżeli osoby oceniające wypowiedź odbierały emocję jako silnie wyrażoną, to zakres zmian w obrębie wykorzystanych parametrów akustycznych głosu był większy. Jeżeli przy realizowaniu różnych emocji wykorzystane środki głosowe były podobne, np. w przypadku radości i gniewu, to im bardziej negatywna była emocja, tym większa była aktywność nagłośniowa towarzysząca jej wyrażaniu.

Duża aktywność mięśniowa okolic gardła dolnego i przedsionka krtani obserwowana była podczas wyrażania w głosie obrzydzenia i pogardy. Jako środek ekspresji tych emocji wykorzystywana była dodatkowa cecha głosu - szorstkość. Podobne zwiększenie aktywności nadgłośniowej stwierdził również Sakakibara [22] podczas badań wokalistów posługujących się celowo szorstkością jako środkiem artystycznego przekazu, np. w muzyce rockowej. Być może ruchy fałdów przedsionkowych w przypadkach celowo wykorzystanej szorstkości powinno się traktować jako czynności potrzebne do uzyskania dodatkowych cech głosu.

\section{Wnioski}

1. Czynność toru nadgłośniowego zależy od jakości tworzonego głosu i intencji wypowiedzi.

2. Większy zakres zmiany w głosie związany jest $\mathrm{z}$ większą aktywnościa mięśniową okolic nadgłośniowych krtani.

3. Podczas tworzenia głosu $z$ intencją emocji większy jest zakres ruchów w obrębie gardła i przedsionka krtani niż podczas tworzenia głosu bez emocji.

\section{Piśmiennictwo:}

1. Damasio A: Emocje i uczucia. W: Damasio A. Tajemnice świadomości. Poznań: Rebis; 2000, 43-90.

2. Golińska L. Samokontrola emocji. Mit czy rzeczywistość. Terapia Uzależnienia i Współuzależnienia, 2000; 6.

3. Scherer KR. Expression of emotion in voice and music. J Voice, 1995; 9(3): 235-48.

4. Morrison M. Pattern recognition in muscle misuse voice disorders: how I do it. J Voice, 1997; 11(1): 108-14.

5. Juslin PN, Scherer KR. Speech emotion analysis. Scholarpedia, 2008; 3(10): 4240.

6. Juslin PN, Laukka P. Communication of emotions in vocal expression and music performance: different channels, same code? Psychol Bull, 2003; 129(5): 770-814.

7. Grichkovtsova I, Morel M, Lacheret A. The role of voice quality and prosodic contour in affective speech perception. Speech Communication, 2012; 54(3): 414-29.

8. Tao J, Kang Y, Li A. Prosody conversion from neutral speech to emotional speech. IEEE Transactions on Audio, Speech, and Language Processing, 2006; 14(4): 1145.

9. Scherer KR, Banse R, Wallbott HG. Emotion inferences from vocal expression correlate across languages and cultures. Journal of Cross-Cultural Psychology, 2001; 32(1): 76-92.

10. Scherer KR. Vocal communication of emotion: A review of research paradigms. Speech Communication, 2003; 40: 227-56.

11. Izdebski K. Emotions of the human voice. Plural Publishing; 2008.

12. Abelin A, Allwood J. Cross linguistic interpretation of emotional prosody. W: Proc. ISCA Workshop (ITRW) On Speech and Emotion: A conceptual frame work for research. Belfa St, 2000.
13. Lee S, Yildirim S, Kazemzadeh A, Narayanan S. An articulatory study of emotional speech production. EUROSPEECH, Lisbon, Portugal, 2005.

14. Lee S, Bresch E, Adams J, Kazemzadeh A, Narayanan SS. A study of emotional speech articulation using a fast magnetic resonance imaging technique. W: Proceedings of Interspeech, Pittsburgh, PA; 2006, 2234-7.

15. Kazanecka E, Szkiełkowska A, Skarżyński H. Kryteria oceny czynności nadgłośniowej części krtani i gardła w czasie tworzenia głosu. Nowa Audiofonologia, 2013; 2(4): 31-5.

16. Koufman JA. Evaluation of laryngeal biomechanics by fiberoptic laryngoscopy. W: Rubin JS, Sataloff RT, Korovin GS i wsp., red., Diagnosis and treatment of voice disorders. New York: Igaku-Shoin; 1995, 122-35.

17. Bielamowicz S, Kapoor R, Schwartz J, Stager SV. Relationship among glottal area, static supraglottic compression, and laryngeal function studies in unilateral vocal fold paresis and paralysis. J Voice, 2004; 18(1): 138-45.

18. Stager S, Bielamowicz S, Regnell J, Gupta A, Barkmeier J. Supraglottic activity: evidence of vocal hyperfunction or laryngeal articulation? J Speech Lan Hear Res, 2000; 43(1): 229-38.

19. Stager S, Neubert R, Miller S, Regnell J, Bielamowicz S. Incidence of supraglottic activity in males and females: a preliminary report. J Voice, 2003; 17(3): 395-402.

20. Stager $S$. The role of the supraglottic area in voice production. Otolaryngology, 2011; S1-001.

21. Tuma J, Pontes P, De Brasil O, Yasaki R. Vestibular folds configuration in vocal nodule. Brasilian Journal of Otorhinolaryngology, 2005; 71(5): 570-81.

22. Sakakibara K, Fuks L, Imagawa H, Tayama N. Growl voice in ethnic and pop styles. Proceedings of the International Symposium on Musical Acoustics. Nara Japan, 2004. 